\title{
UMA SOCIÓLOGA NA CIDADE: Sylvia \\ Ostrowetsky em Brasília
}

\author{
Brasilmar Ferreira Nunes*
}

O trabalho intelectual nos coloca à mão autores das mais diferentes estirpes. Muitos passam despercebidos, outros tocam-nos de forma particular e passamos a utilizar suas reflexões como pano de fundo para as nossas atividades profissionais. Se excetuarmos os clássicos de nossa disciplina, com suas obras fundadoras às quais recorremos como a uma bíblia, autores contemporâneos submetidos à lógica utilitarista que envolveu a ciência contemporânea terminam por nos alimentar com reflexões muitas vezes absolutamente abstratas, sem o imprescindível esforço do contato na realidade empírica. Isso traz como resultado os autores da moda, que passam com a rapidez que o momento impõe. A filtragem do que nos chega às mãos termina sendo uma de nossos principais exercícios intelectuais.

Sylvia Ostrowetsky é uma dessas intelectuais que, no seu estilo próprio, trouxe contribuições significativas para o estudo do espaço urbano, embora não tenha se transformado em vida numa referência de moda. Entre o livro que é sua tese de doutorado, os artigos que publicou em periódicos, sobretudo franceses, e os colóquios que organizou, tem ela uma produção densa e instigante que inova o pensamento sociológico sobre a cidade, bastante útil para refletirmos sobre a lógica urbana.

Seu pensamento é denso, diria mesmo hermético. Não se lê os seus textos; eles nos obrigam a estudá-los, a compreendê-los nas entrelinhas. Talvez por isso a dificuldade em utilizá-los em nossas práticas intelectuais. Neste sentido, a tentativa que farei de trabalhar a percepção de Brasília dentro da perspectiva de análise de Sylvia Ostrowetsky é um texto exploratório, justamente em vista da extrema complexidade de seu pensamento e de sua perspicácia intelectual, a qual tenho limites para alcançar.

\footnotetext{
Pofessor titular do Departamento de Sociologia da UnB; pesquisador do CNPq. Esta resenha foi publicada também na Revista do Livro Universitário, n. 15, ago. 2003.

Artigo recebido em 24 ago. 2004; aprovado em 27 nov. 2004.
} 
Ela visitou nossa cidade algumas vezes na vida, e em algumas delas tivemos oportunidade de circular pelo Plano Piloto para que ela pudesse conhecê-lo. ${ }^{1}$ É interessante chamar a atenção para o fato de que nós, moradores de um lugar, nos habituamos à paisagem e fazemos dela algo corriqueiro. É por isso que visitar nossa cidade na companhia de um estrangeiro, tendo que detalhar aspectos que para nós são parte constitutiva da paisagem do dia-a-dia é como re-encarar de outra maneira algo que nos parece absolutamente banal. Um espaço racional adquire sentido através das práticas de uso e nós, moradores, construímos mentalmente o lugar à medida que o percorremos.

Particularmente no caso de Sylvia Ostrowetsky a oportunidade era ímpar, pois havia defendido uma tese de doutorado " $d$ 'État" onde estuda cidades novas na França ${ }^{2}$ e pour cause Brasília era uma de suas principais referências de planejamento urbano no mundo. Tratava-se portanto de uma intelectual muito especial, particularmente para mim que tento entender em meus trabalhos de pesquisa a lógica social do espaço de Brasília.

Lembro-me da primeira vez que entramos na Esplanada dos Ministérios, saindo da Universidade de Brasília, vindo pela L2 Norte. A primeira visão é a Catedral (ela praticamente monopoliza o olhar), alguns edifícios ao fundo; à direita, um vazio e a pirâmide do Teatro Nacional com a plataforma da rodoviária; e, à esquerda, um enorme espaço verde vazio, com prédios absolutamente iguais de ambos os lados (os Ministérios), limitados ao fundo pelo edifício do Congresso Nacional (outra referência do lugar, embora sem o apelo da Catedral). Um desenho cartesiano, original, mas, para mim, uma paisagem corriqueira, banal, mas que provocou naquela "estrangeira" uma excitação e um entusiasmo que me surpreenderam, especialmente vindo de uma socióloga e não de uma arquiteta. Finalmente, não se via ninguém no fim de semana naquele espaço, o que para um sociólogo é quase a ausência de objeto de análise, ou o não-objeto. Trabalhamos com pessoas e suas formas de interação, de vínculo, e ali, à nossa frente, estava um conjunto de edificações, esteticamente originais, porém sem ninguém, com alguns poucos veículos circulando. 
Lendo parte de sua produção intelectual tentarei visitar Brasília com Sylvia. Há na sua militância intelectual uma permanente tentativa de explicitar os vínculos estreitos que ligam o urbanismo e as ciências humanas. Segundo ela, mesmo se há uma desconfiança geral em face da sua complexidade e da sua capacidade crítica, da sua intransigência em não querer passar da objetividade da constatação a um dever-fazer, as ciências humanas se tornam os novos instrumentos da prática urbanística. De fato, as ciências humanas e sociais, na perspectiva de Sylvia Ostrowetsky estão operando aquilo que a Física realizava no começo do século XX: "ela nos mostra que não podemos mais considerar como uma coisa em si as pedras da matéria, as quais eram tomadas pela realidade objetiva última (...). A divisão convencional do mundo em sujeito e objeto, em mundo interior e em mundo exterior, em corpo e alma não pode mais ser utilizada (...) o sujeito da pesquisa não é então mais a natureza em si, mas a natureza dada à interrogação humana e, neste sentido, o homem, de novo, vai se reencontrar".

Entre seu entusiasmo e seus comentários (de alguém cuja prática intelectual tinha no espaço construído um dos seus objetos preferidos), imediatamente me dei conta, mais uma vez, que Brasília é, de fato, um caso único, uma experiência original de implantação de um projeto arquitetônico de cidade que acontece quase que de forma idêntica ao que foi planejado pelos urbanistas e arquitetos. Mesmo se considerarmos que o projeto original sofreu na sua implantação algumas alterações, não se pode negar que se trata de um caso exemplar. Exemplar em alguns aspectos que vale a pena enumerar:

- A concretização de um modelo de urbanismo tal qual definido em congressos internacionais de arquitetura;

- Um projeto que se desenha a partir de critérios estéticos de um pequeno grupo de profissionais que não encontram barreiras sociais, políticas ou mesmo culturais para proporem suas idéias; 
- Um projeto arquitetônico que se insere num projeto de nação em curso e que se transforma na síntese de um modelo de sociedade naquilo que isto pode conter de utopia.

Mas não era somente isso que entusiasmava a nossa visitante. $\mathrm{O}$ fato de ser o resultado de um projeto desenvolvido em um escritório de arquitetura, dá a Brasília a característica similar à de uma obra de arte, de uma pintura: o pintor, o criador da obra de arte transmite no seu quadro algo que reflete a intensidade de sua libido. Analisar Brasília como obra arquitetônica é algo nessa direção: é arte, é desejo de um(s) arquiteto(s) que se faz realidade. Mas olhá-la sob esta ótica seria como se estivéssemos descrevendo o trabalho desenvolvido pelos arquitetos ao invés de descrever o "lugar", o significado do "gesto primário". Como nos diz Sylvia Ostrowetsky, esta seria também uma maneira de refletir sobre Brasília. Finalmente, o espaço do sonho é exatamente uma metáfora espacial do desejo. Mas nós, das ciências sociais, temos o direito de reivindicar o espaço como "lugar" no senso próprio e figurado: dispositivo e retórica.

De fato, fui compreender todo o seu interesse a partir da leitura de alguns de seus textos. Particularmente, vou me arriscar a entrar na discussão que ela elabora entre "símbolo" e "sociedade". Penso que aí está o cerne de seu entusiasmo por Brasília.

Em seu livro L'imaginaire bâtisseur, de 1983, Ostrowetsky procura refletir sobre a relação símbolo e identidade. Fazendo referência à freqüente confusão que se faz entre símbolo, imagem e signo, diz ela: "Enquanto o imaginário designa a esfera da imaginação, os símbolos são considerados como as figuras particulares, relativamente fixas, desta esfera genérica. Entre simbólico e imaginário se estabelece uma cumplicidade quase perfeita pois o imaginário é definido como o solo originário dos símbolos, das imagens, mesmo dos signos" (p. 21). Na sua reflexão sobre cidades novas, ela nos alerta sobre a imposição mesma do objeto no sentido de diferenciar o simbólico do imaginário. Para levar a cabo sua proposta, vai utilizar sucessivamente a abordagem antropológica, a psicanalítica e a filosófica. Há em sua análise a tomada de partido do simbólico como 
elemento constitutivo do fato social que se apresenta segundo uma dupla característica: "universalismo, de um lado, e particularismo, de outro, numa permanente tentativa de re-territorialização e de fincar raízes em face do nomadismo do capitalismo".

Esta perspectiva é interessante para se pensar Brasília. A sua arquitetura, o seu desenho urbanístico cria referências originais, novas para uma nação então em processo de aceleradas mudanças. Não se poderia repetir esquemas ou padrões estéticos - e portanto culturais - do então existente em nossas cidades. Tratava-se de uma cidade nova para uma nova sociedade. Analisada nesta dimensão, podemos nos dar conta da enorme força que as linhas arquitetônicas de Brasília adquiriram como símbolo do Brasil a partir de então. Basta imaginar a impossibilidade, hoje, de se pensar a nação sem referência à arquitetura de sua capital para nos darmos conta do significado dos símbolos na construção da identidade. Assim, podemos junto com Sylvia Ostrowetsky insistir no espaço como dimensão constitutiva da sociedade, o que significa avaliá-lo não apenas como suporte técnico de uma atividade ou suporte simbólico de uma organização, não somente como produto ou meio, mas simultaneamente inconsciente e materialidade (Sociologues en ville, 2000, p. 15). Há entre espaço e sociedade uma relação dialética no sentido em que o social é, também, inversamente uma dimensão constitutiva do espaço. Entre sujeito e objeto há, portanto, uma lógica onde o sujeito se apresenta e constrói um objeto, mas também um objeto que aparece ao sujeito, e se apresenta e propõe a este mesmo sujeito sua própria lógica de objeto.

É encarando desta forma que o sociólogo pode compreender como a concepção de espaço e de arquitetura de Brasília é um dos aspectos constitutivos da natureza dos vínculos sociais que aqui se estabelecem: uma materialidade espacial, um suporte que se infiltra no inconsciente dos usuários deste espaço e que redefine as suas percepções de cidade, de relações de vizinhança, de relações de trabalho e, sobretudo, suas percepções de tempo e território. Neste sentido pode-se conceber em uma outra perspectiva o urbanismo: 
não é apenas uma gestão, uma construção representativa da sociedade; ele é, em si mesmo, parte constitutiva desta sociedade e deste espaço. Em outras palavras, o espaço em geral - e o de Brasília em especial - participa, à sua maneira, das exigências sociais e culturais da produção de sentido. Ele identifica o habitante da cidade, o seu usuário, e identifica, neste caso, simultaneamente o brasileiro. ${ }^{3}$

Brasília, como espaço urbano produto de um urbanismo estatal, utiliza o modelo praticamente universal de zoneamento funcional. Em praticamente todos os casos analisados em experiências as mais diversas no mundo, se constata que, por mais que as melhores das intenções estivessem na base da concepção destes espaços novos, os habitantes invariavelmente abandonam os grandes conjuntos assim que podem, à medida que assimilam sua lógica pseudo-racional a uma perda de sentido. Há para o caso de Brasília uma figura de exceção. Talvez seja esta que entusiasma Sylvia Ostrowetsky quando visualiza pela primeira vez a Esplanada dos Ministérios. A cidade escapa a esta lógica de exceção e isso a torna um fato absolutamente original no universo das cidades novas do século XX. Sua concepção de espaço construído nos permite deduzir esta perspectiva: "Por causa de seu peso físico, ele (o espaço construído) é suporte; por causa de suas formas de acolhimento, ele é a moldura cultural; por causa de seus "jogos de linguagem” próprios, ele é o agente de troca e de organização interna. Dito de outra forma, se o espaço construído é um dos "objetos" dos mais controlados pelos Estado, é porque ele pesa com toda força 'argumentativa', ou seja, estratégica, na vida social” (Sociologues en ville, 2000, p. 144).

Brasília, como capital política, torna-se também lugar das manifestações coletivas. A Esplanada dos Ministérios quando é utilizada como espaço de protesto mostra que a ordem mecânica de uso do espaço entre pistas de automóveis e calçadas de circulação mecânica, impondo o ritmo, o parar, o seguir opondo a rapidez à indiferença habitual, estes protestos descrevem uma "estratégia de transgressão inteiramente baseada na utilização simbólica de um grupo social coagulado em um corpo fisicamente reunido e reperável”. Uma cidade máquina que se mostra corpo vivo, submetido a contradições 
na sua extrema racionalidade funcional evidenciando a estreita relação, às vezes contraditória, entre o simbólico do espaço e a ordem do social. Hoje, um protesto político na Esplanada dos Ministérios tem mais visibilidade do que em qualquer outro espaço urbano do país. Isso é a prova de que a nação se enxerga naquele território e o usa inclusive para manifestar suas expectativas, seus descontentamentos, suas alegrias.

Há outras entradas possíveis para se trabalhar Brasília com Sylvia Ostrowetsky. Muitas delas nunca antes exploradas por nós. Penso que sua obra fica como legado do potencial que as ciências humanas, particularmente a Sociologia, têm para, em conjunto com outras ciências e/ou disciplinas, refletir sobre o significado e as implicações de gestos, atos, planos que resultam em territórios coletivos produtores de sociedades, como são os das cidades.

Uma derradeira reflexão: Sylvia Ostrowetsky utiliza com certa freqüência em seus textos trabalhos de Merleau-Ponty. Fui procurar alguma referência do por quê dessa escolha. De fato, paradoxalmente, pelo menos num primeiro olhar, em Merleau-Ponty o que interessa diretamente à questão da cidade é o estudo da percepção, lá onde o problema das relações da alma e do corpo é colocado em novos termos: "Sua originalidade consiste em combater o empirismo e o intelectualismo partindo da consciência situada e concreta. O novo cogito é então o corpo, não no sentido de corpo-objeto, mas no sentido no qual eu sou meu corpo, uma espacialidade apreendida além da redução mecanicista" (2000, p. 401). Corpos (espaços, territórios) movem-se num "suporte construído" (cidade) que lhe dá sentido e para o qual ele é também produtor de sentido. Em síntese, pensar a cidade, equivaleria a pensar a interconexão de corpos, de vínculos, de territórios.

\section{Notas}

1 Outros amigos a levaram para as diferentes satélites de Brasília, pois sua curiosidade não se restringia ao Plano Piloto, mas também aos seus 
efeitos diretos e indiretos sobre as outras formas de ocupação do espaço que se implementa no Distrito Federal.

2 L'imaginaire bâtisseur, defendida em 1980 e publicada em 1983.

3 "O sentido do espaço social é o produto direto de um uso, da mesma forma que a cruz como símbolo é o produto direto do calvário de Cristo" (Sociologues en ville, 2000, p. 146).

\section{Referências bibliográficas}

OSTROWETSKY, Sylvia. Um géant tombe du ciel. Revue Che vuoi, n. 3, 1995.

. L'imaginaire bâtisseur. Paris: Méridiens-Klincksieck, 1983. . Sociologues en ville. Paris: L'Harmattan, 2000.

OSTROWETSKY, S.; BORDREUIL, J. S. Le néo-style régional. Paris: Dunod, 1980.

MERLEAU-PONTY, M. Phénomenologie de la perception. In: ANSAY, P.; SCHOONBRODT, R. (Org.). Penser la ville: choix de textes philosophiques. Bruxelas: AAM Éditions, 2000. 